\title{
Selective Cloud Point Extraction and Preconcentration of Trace Amounts of Cadmium Prior to Flame Atomic Absorption Spectrometric Determination
}

\author{
Shayesteh Dadfarnia,* Ali Mohammad Haji Shabani and Ellahe Kamranzadeh \\ Department of Chemistry, Yazd University, Safaieh, 89195, Yazd, Iran
}

\begin{abstract}
A extração por ponto nuvem (CPE) é proposta como um procedimento de separação e préconcentração para a determinação de cádmio em amostras de água por espectrometria de absorção atômica com chama associada a sistema de injeção em fluxo (FI-FAAS). O íon cádmio em solução aquosa foi convertido a $\left[\mathrm{CdI}_{4}\right]^{2-}$ e sua carga foi neutralizada pela formação do par iônico com o cátion metiltrioctilamônio na presença de TritonX-114 como surfactante não iônico. A separação de fases foi obtida pelo aquecimento da mistura a $80{ }^{\circ} \mathrm{C}$ por $10 \mathrm{~min}$. A fase rica em surfactante foi diluída com $300 \mu \mathrm{L}$ de etanol e $100 \mu \mathrm{L}$ foram analisados por FI-FAAS. Os parâmetros que influenciam a formação do par iônico e extração foram otimizados. Sob condições ótimas, a préconcentração de $35 \mathrm{~mL}$ de amostra na presença de $0,04 \%$ (v/v) de Triton X-114 possibilitou um limite de detecção de $0,3 \mu \mathrm{g} \mathrm{L^{-1 }}$ de Cd(II). A curva analítica de calibração foi linear até $250 \mu \mathrm{g} \mathrm{L}^{-1}$ de cádmio e o desvio padrão relativo foi inferior a $4 \%$ para uma solução contendo $100 \mu \mathrm{g} \mathrm{L}^{-1}$ de Cd. O procedimento gerou recuperações no intervalo de $95-102 \%$. O procedimento foi aplicado com sucesso para a determinação de cádmio em água de torneira, água de mar e em material de referência certificado de concentrado de cobre.
\end{abstract}

Cloud point extraction (CPE) is proposed as a separation and preconcentration procedure for determination of cadmium in water samples by flow injection flame atomic absorption spectrometry (FI-FAAS). The cadmium ion in aqueous solution was converted to $\left[\mathrm{CdI}_{4}\right]^{2-}$ and its charge was neutralized through ion-pair formation with methyltrioctylammonium cation in the presence of Triton X-114 as a non ionic surfactant. Phase separation was achieved by heating the mixture to $80{ }^{\circ} \mathrm{C}$ for $10 \mathrm{~min}$. The surfactant-rich phase was diluted with $300 \mu \mathrm{L}$ of ethanol and $100 \mu \mathrm{L}$ of it was analysed by FI-FAAS. The parameters affecting the ion-pair formation and extraction steps were optimized. Under optimum condition, preconcentration of $35 \mathrm{~mL}$ of sample in the presence of $0.04 \%$ (v/v) of Triton X-114 led to a detection limit of $0.3 \mu \mathrm{g} \mathrm{L}^{-1}$ of Cd(II). Analytical calibration curve was linear up to $250 \mu \mathrm{g} \mathrm{L}^{-1}$ of cadmium and relative standard deviation was lower than $4 \%$ at $100 \mu \mathrm{g} \mathrm{L}^{-1}$ level. The procedure affords recoveries in the range of $95-102 \%$. The procedure was successfully applied to the determination of $\mathrm{Cd}$ in tap water, sea water and certified reference copper concentrate.

Keywords: cloud point preconcentration, cadmium ion determination, FI-FAAS, Trion X-114, water samples, ore

\section{Introduction}

Cadmium is highly toxic even at very low concentrations causing damages to organs such as kidneys, liver and lungs. ${ }^{1}$ The exposure is obviously dependent upon the emission of the element and might be particularly serious in some factories; $50 \%$ of inhaled cadmium for example, is absorbed and most of it is concentrated in the liver and kidney. ${ }^{2}$ The deposition of cadmium which occurred during the $20^{\text {th }}$ century, leds to continuous increase of its concentration in

*e-mail: sdadfarnia@yazduni.ac.ir terrestrial and aquatic ecosystems, hence exposing human and wildlife to critical levels of this element. For humans, the main source of cadmium is water and food. Therefore, sensitive, reproducible and accurate analytical methods are required for the determination of trace amount of cadmium in such samples.

Graphite furnace atomic absorption spectrometry (GFAAS) and inductively coupled plasma mass spectrometry (ICP-MS) are the most sensitive techniques for the determination of trace level of metals. ${ }^{3,4}$ However, flame atomic absorption spectrometry (FAAS) is widely used for these determinations due to the common availability 
of the instrumentation, the simplicity of procedures and the speed, precision and accuracy of the techniques . But, its limitation is low detectability, which may be improved by a preconcentration step. ${ }^{5-9}$ Several methods for the separation and preconcentration of metals have been developed, enhancing the sensitivity and the versatility of the instrumental analytical techniques.

In the last decade, cloud point extraction (CPE) has attracted considerable attention mainly because it complies with the Green Chemistry principle..$^{710-12}$ as the amount of organic solvent is lower than the conventional solvent extraction and the surfactant can be incinerated in the presence of waste acetone or ethanol. Since the first application of this technique for metal extraction, ${ }^{12}$ numerous paper has reported the use of CPE as preconcentration procedure for metal determination by several spectrometric techniques. ${ }^{10-20}$ The principle, advantages and limitation of this technique, have been summarized in several reviews. ${ }^{10,11}$

Several ligands such as 1-(2-thiazolylazo)-2-naphtol (TAN), ${ }^{21-23} O, O$-dietyldithiophosphate (DDTP) ${ }^{23,24}$ and dithizone ${ }^{25}$ have been used in CPE and FAAS determination of cadmium. In this study, the possibility of extraction of cadmium as ion-pair by CPE was considered. Cadmium in aqueous samples was converted to $\left[\mathrm{CdI}_{4}\right]^{2-}$ and was extracted as ion pair with methyltrioctylammonium cation into surfactant rich phase and was determined by FI-FAAS. The optimized procedure was applied to water samples and copper flotation standard reference material.

\section{Experimental}

\section{Instrumentation}

A Buck scientific atomic absorption spectrometer (Model 210 VGP, USA) was utilized, equipped with a deuterium background correction and an air-acetylene flame. A cadmium hollow-cathode lamp was used as radiation source, operated at $8.2 \mathrm{~mA}$ with a monochromator spectral resolution of $0.7 \mathrm{~nm}$. For the cadmium detection, the wavelength was set at $228.8 \mathrm{~nm}$ resonance line. The single line flow injection system consisting of peristaltic pump (Ismatec, MS-REGLO/8-100, Switzerland), and rotary injection valve (Rheodyne, CA, USA) with a loop of $100 \mu \mathrm{L}$ capacity was used for effective control of the amount of sample and reproducibility of the measurement. The absorbance time response was monitored on $\mathrm{x}$-t chart recorder (L-250) and quantitative analysis was based on measurement of the peak height of transient signals. The $\mathrm{pH}$ values were measured with a Metrohm pH-water (Model 691, Switzerland) supplied with a glass-combined electrode.

\section{Reagents and solutions}

The cadmium stock solution ( $1000 \mathrm{mg} \mathrm{L}^{-1}$ ) was prepared by dissolving appropriate amount of $\mathrm{Cd}\left(\mathrm{NO}_{3}\right)_{2}$ (Merck, Darmstadt, Germany) in $1 \%(\mathrm{v} / \mathrm{v})$ nitric acid solution. The working standard solutions were prepared by serial dilutions of the stock solution prior to analysis. All solutions were stored in pre-cleaned polypropylene (Nalgene, Lima, OH, USA) containers. Methyltrioctylammonium chloride was obtained from Merck and the solution of methyltrioctylammonium $\left(0.2 \mathrm{~mol} \mathrm{~L}^{-1}\right)$ was prepared by dissolving proper amount of it in ethanol. Triton X-114 solution ( $2 \% \mathrm{v} / \mathrm{v}$ ) was prepared by proper dilution of the commercially available product with water. All other chemicals were of highest purity available from Merck and were used as received and deionized water was used throughout the experiments. The tap water, well water and sea water samples were collected in PTFE containers, stored in a dark place at $4{ }^{\circ} \mathrm{C}$, and were analyzed within $24 \mathrm{~h}$ of collection. The seawater was filtered through a membrane filter $(25 \mathrm{~mm}$ in diameter, porosity $0.45 \mu \mathrm{m}$, Dura pore TM, Millipore) prior to analysis. The reference ore sample was prepared by adding $5 \mathrm{~mL}$ of concentrated nitric acid to $0.105 \mathrm{~g}$ of reference ore material (CCU-1b) and heating the sample on a water bath for few minutes. The sample was then filtered through a Millipore filter, $10 \mathrm{~mL}$ of $0.2 \mathrm{~mol} \mathrm{~L}^{-1}$ glycine was added, and the $\mathrm{pH}$ was adjusted and was treated according to the given procedure.

\section{Procedure}

For CPE, $35 \mathrm{~mL}$ of sample or standard solution of cadmium was made $0.1 \mathrm{~mol} \mathrm{~L}^{-1}$ with respect to $\mathrm{I}^{-}$and its $\mathrm{pH}$ was adjusted to $c a$. 1.5 with hydrochloric acid. Then, $1.75 \mathrm{~mL}$ of methyltrioctylammonium chloride in ethanol $\left(0.2 \mathrm{~mol} \mathrm{~L}^{-1}\right)$ and $0.70 \mathrm{~mL}$ Triton X-114 (2\%, v/v) were added to this solution. The mixture was heated in a thermostated water bath at $80{ }^{\circ} \mathrm{C}$ for $10 \mathrm{~min}$. The solution becomes cloudy at this stage. To separate the phases the mixture was centrifuged for $10 \mathrm{~min}$ at $3500 \mathrm{rpm}$. Afterwards, the solution was cooled in ice-bath for $10 \mathrm{~min}$, and the micellar phase was separated by simply inverting the tube to discard the aqueous phase. Finally, in order to reduce the viscosity and facilitate sample handling, the micellar phase was diluted to $0.5 \mathrm{~mL}$ with ethanol and $100 \mu \mathrm{L}$ of the resultant solution was introduced into the FAAS for quantification by using a single line FI system (Figure 1).

\section{Results and Discussion}

The separation of metal ions by CPE method involves prior formation of an adduct with sufficient hydrophobicity 


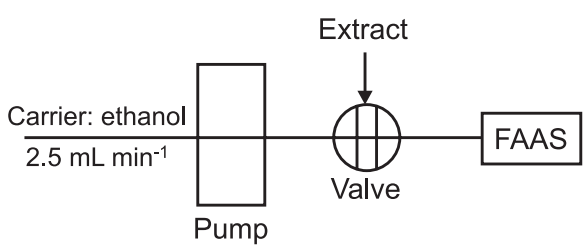

Figure 1. Schematic of flow injection system coupled to flame atomic absorption spectrometry.

to be extracted into the small volume of surfactant-rich phase, thus obtaining the desired preconcentration. ${ }^{18}$ Cadmium easily form negatively charged complex with iodide ${ }^{26}$ $\left(\left[\mathrm{CdI}_{4}\right]^{2-} \log \beta_{4}=5.35\right)$ which is hydrophilic; however, it forms a lipophilic ion pair with methyltrioctylammonium chloride [MTOA] which is extractable into organic liquid such as 1-undecanol. ${ }^{27}$ In the preliminary study it was established that ion pair of $\left[\mathrm{CdI}_{4}\right]^{2-}$ with MTOA can also be extracted into the surfactant rich media. The process can be summarized as:

$$
\begin{aligned}
& {\left[\mathrm{CdI}_{4}\right]^{2-}{ }_{(\mathrm{aq})}+2 \mathrm{CH}_{3}\left(\mathrm{n}-\mathrm{C}_{8} \mathrm{H}_{17}\right)_{3} \mathrm{~N}^{+}{ }_{(\mathrm{aq})} \rightarrow} \\
& {\left[\mathrm{CdI}_{4}{ }^{2-}\right]\left[2 \mathrm{CH}_{3}\left(\mathrm{n}-\mathrm{C}_{8} \mathrm{H}_{17}\right)_{3} \mathrm{~N}^{+}\right]_{2 \text { (srp) }}}
\end{aligned}
$$

"srp" and "aq" represent the "surfactant rich phase" and "aqueous phase" respectively. Then, the parameters affecting the adduct formation and the extraction conditions such as concentration of iodide, $\mathrm{pH}$, surfactant and MTOA concentration, temperature and incubation time were optimized using a univariate approach.

The pH plays a unique role on the metal-adduct formation and subsequent separation by CPE. So, the effect of $\mathrm{pH}$ on the CPE extraction of cadmium was studied in the $\mathrm{pH}$ range of 0.25-5 using hydrochloric acid or ammonium hydroxide. The results illustrated in Figure 2 shows that the recovery is nearly constant in the $\mathrm{pH}$ range of 1-2.5. Owing to this behavior the $\mathrm{pH}$ value of 1.5 was selected as the working value.

The effect of concentration of iodide on conversion of cadmium to $\left[\mathrm{CdI}_{4}\right]^{2-}$ and its recovery from aqueous phase was studied by extracting $5 \mu \mathrm{g}$ of cadmium from $35 \mathrm{~mL}$ of a solution ( $\mathrm{pH} \mathrm{ca}$. 1.5) containing MTOA $\left(0.1 \mathrm{~mol} \mathrm{~L}^{-1}\right)$ and Triton X-114 $(0.04 \% \mathrm{v} / \mathrm{v})$ plus various amount of potassium iodide. The results, presented in Figure 3, revealed that the recovery of cadmium was increased with an increase in iodide concentration up to $0.1 \mathrm{~mol} \mathrm{~L}^{-1}$ and was constant up to $0.2 \mathrm{~mol} \mathrm{~L}^{-1}$. It should be mentioned that the slight decrease in recovery in the presence of excess amount of iodide might be due to the extraction of excess amount of iodide as ion pair with MTOA into small volume of micelle phase, causing its saturation. In this study concentration of $0.1 \mathrm{~mol} \mathrm{~L}^{-1}$ of iodide was selected for subsequent experiments.

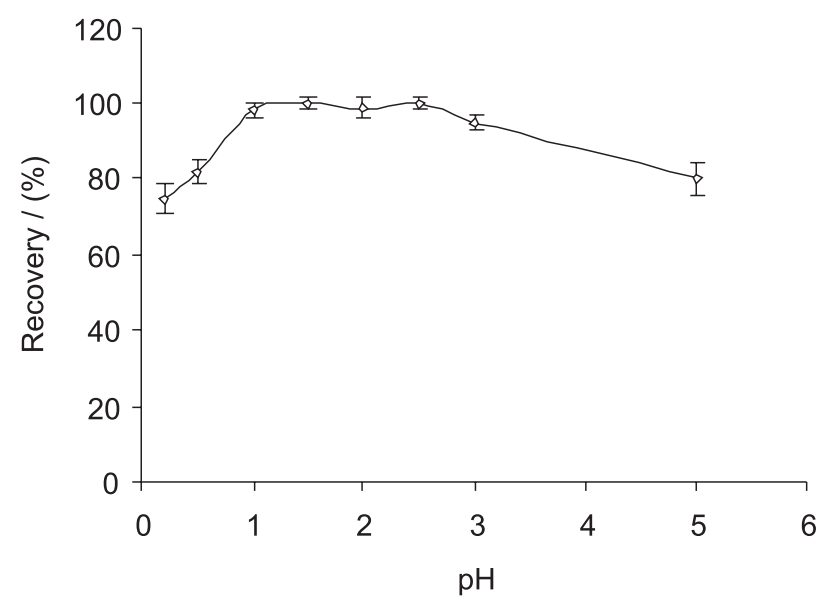

Figure 2. Effect of $\mathrm{pH}$ on extraction of cadmium by CPE method. Extraction conditions: sample volume, $35 \mathrm{~mL}$; amount of metal ion, $7 \mu \mathrm{g}$; Triton X-114, $0.04 \%$ (v/v); iodide $0.1 \mathrm{~mol} \mathrm{~L}^{-1}$; methyltrioctylammonium chloride $0.1 \mathrm{~mol} \mathrm{~L}^{-1}$.

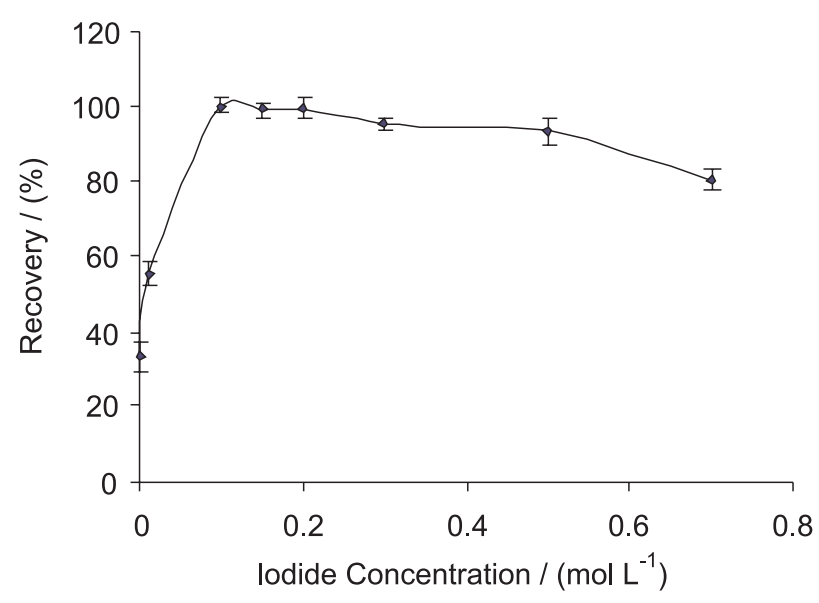

Figure 3. Effect of iodide concentration on extraction of cadmium by CPE method. Extraction conditions: sample volume, $35 \mathrm{~mL}$; amount of metal ion, $7 \mu \mathrm{g}$; $\mathrm{pH}$ ca. 1.5; Triton X-114, 0.04\% (v/v); methyltrioctylammonium chloride $0.1 \mathrm{~mol} \mathrm{~L}^{-1}$.

The effect of concentration of MTOA on extraction of cadmium was subsequently studied and the results are shown in Figure 4. The recovery increased with an increase in MTOA concentration up to $9.2 \times 10^{-2} \mathrm{~mol} \mathrm{~L}^{-1}$ which was sufficient for adduct formation. The extraction was independent of further increase in the amount of MTOA. Thus a concentration of $0.1 \mathrm{~mol} \mathrm{~L}^{-1}$ of MTOA was selected as optimum.

An optimized equilibration temperature and incubation time is necessary for completion of reaction, achievement of phase separation and quantitative extraction and preconcentration. It is desirable to employ the shortest incubation time and the lowest possible equilibration temperature which fulfilled these requirements. The temperature at which the sample solution is heated was varied in the range of $25-90^{\circ} \mathrm{C}$, and was found that in the temperature range of $75-90{ }^{\circ} \mathrm{C}$ the reaction is completed 


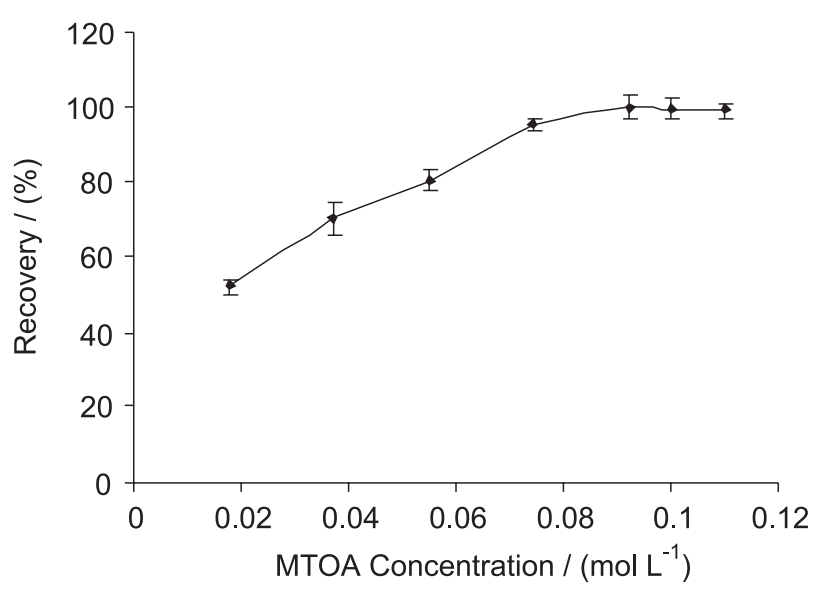

Figure 4. Effect of MTOA concentration on extraction of cadmium by CPE method. Extraction conditions: water sample volume, $35 \mathrm{~mL}$; amount of metal ion, $7 \mu \mathrm{g}$; $\mathrm{pH}$ ca. 1.5; Triton X-114, $0.04 \%$ (v/v); iodide $0.1 \mathrm{~mol} \mathrm{~L}^{-1}$.

and the phases are efficiently separated. An equilibration temperature of $80{ }^{\circ} \mathrm{C}$ was selected for further studies. The effect of incubation time on extraction was studied by varying the incubation time between 5 to $35 \mathrm{~min}$. An incubation time of $10 \mathrm{~min}$ was found to be sufficient for quantitative extraction.

A successful CPE should maximize the extraction efficiency by minimizing the phase volume ratio $\left(\mathrm{v}_{\mathrm{org}} / \mathrm{v}_{\mathrm{aq}}\right)$ thus improving its concentration ability. The non-ionic surfactant Triton X-114 was chosen due to its commercial availability in a high purified homogenous form, low toxicological properties and cost, low cloud point temperature and high density of surfactant rich phase, which facilitates phase separation by centrifugation. Figure 5 shows the effect of surfactant concentration on the extraction efficiency. It was proved that Triton X-114 effectively extracts adduct of cadmium ions from liquid samples at concentration of $0.04 \%(\mathrm{v} / \mathrm{v})$. Larger quantities of the surfactant can be used at the expense of detection limits, as higher concentration deteriorate atomic signal due to the increase in the surfactant volume. The decrease in extraction at low concentration of surfactant is probably due to its inadequacy of assemblies to entrap the hydrophobic complex quantitatively. The surfactant concentration of $0.04 \%(\mathrm{v} / \mathrm{v})$ was selected for subsequent work and the recovery of analyte was quantitative in a single step process. The preconcentration capability of CPE system was further considered by studying the effect of aqueous volume on recovery of $5 \mu \mathrm{g}$ of cadmium from different sample volume (5-40 mL). The results showed that the extraction was quantitative with the aqueous phase volume up to $35 \mathrm{~mL}$, and then decreased with further increase in sample volume. Thus based on final extract volume $(0.5 \mathrm{~mL})$ and the maximum sample volume that the extraction was quantitative $(35 \mathrm{~mL})$ a preconcentration factor of 70 was determined.

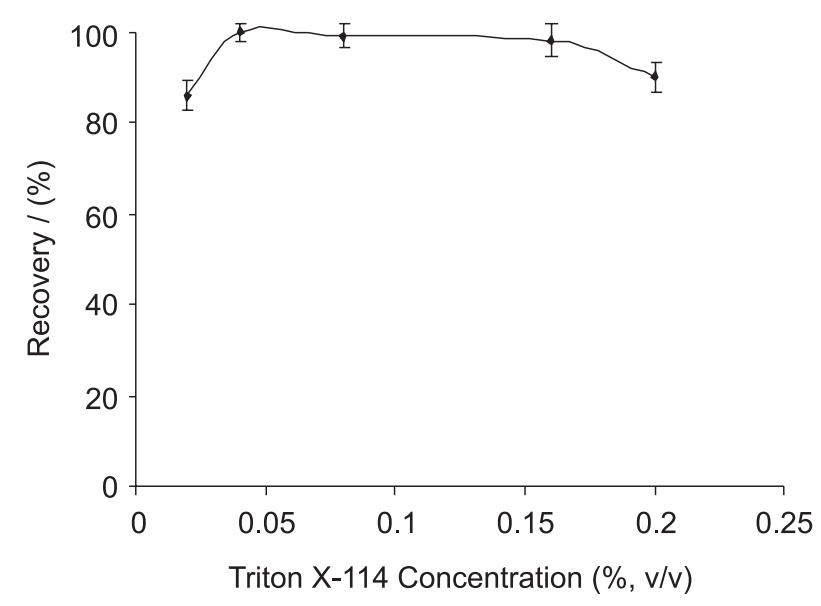

Figure 5. Effect of Triton $\mathrm{X}-114$ concentration on extraction of cadmium by CPE method. Extraction conditions: water sample volume, $35 \mathrm{~mL}$; amount of metal ion, $7 \mu \mathrm{g}$; $\mathrm{pH} c a$. 1.5 ; iodide $0.1 \mathrm{~mol} \mathrm{~L}^{-1}$; methyltrioctylammonium chloride $0.1 \mathrm{~mol} \mathrm{~L}^{-1}$.

\section{Interferences}

The efficiency of the method in extraction and preconcentration of cadmium ion in the presence of potential interference ions in natural waters was examined. For this purpose, the concentration of cadmium was set at $200 \mu \mathrm{g} \mathrm{L}{ }^{-1}$, the concentration of Triton X-114 was set at $0.04 \%(\mathrm{v} / \mathrm{v})$ and that of iodide and MTOA at $0.1 \mathrm{ml} \mathrm{L}^{-1}$. The tolerance limit of coexist ions is defined as the largest amount making variation lower than $5 \%$ in the recovery of analyte. The results of this study are shown in Table 1, and prove that cadmium recovery is quantitative in the presence of excessive amount of the possible interfering ions.

\section{Analytical performance}

Calibration curve was obtained by processing $35 \mathrm{~mL}$ of standard solution of cadmium under the optimized experimental conditions. The calibration curve was linear up to $250 \mu \mathrm{g} \mathrm{L} \mathrm{L}^{-1}$ of cadmium with the equation of $\mathrm{H}=1.81 \times 10^{-2} \mathrm{C}+0.367$ (where $\mathrm{H}$ is the peak height absorbance, and $\mathrm{C}$ is the concentration of analyte) and correlation coefficient of 0.999 . The equation of calibration curve without preconcentration was $\mathrm{H}=2.96 \times 10^{-4} \mathrm{C}+$ 0.125 , thus the enhancement factor, calculated as the ratio of slope of calibration curve obtained by preconcentration of sample to that obtained without preconcentration was found to be 63. The limits of detection and quantification defined as $3 \mathrm{~S}_{b} / \mathrm{m}$ and $10 \mathrm{~S}_{b} / \mathrm{m}$ respectively (where $S_{b}$ is the standard deviation of the blank and $\mathrm{m}$ is the slope of the calibration graph) was found to be 0.3 and $1.0 \mu \mathrm{g} \mathrm{L}^{-1}$. The relative standard deviation (R.S.D.) for seven replicate measurements at $100 \mu \mathrm{g} \mathrm{L}^{-1}$ of $\mathrm{Cd}(\mathrm{II})$ was $4 \%$. The 
Table 1. Effect of foreign ions on the recovery of cadmium $\left(200 \mu \mathrm{g} \mathrm{L}^{-1}\right)$

\begin{tabular}{|c|c|c|c|c|c|}
\hline Ions & $\begin{array}{l}\text { Molar ratio } \\
\text { (ion/Cd(II)) }\end{array}$ & Recovery/(\%) & Ions & $\begin{array}{l}\text { Molar ratio } \\
(\text { ion/Cd (II)) }\end{array}$ & Recovery/(\%) \\
\hline $\mathrm{K}^{+}$ & 1000 & $103 \pm 2$ & $\mathrm{Ni}^{2+}$ & 750 & $96 \pm 2$ \\
\hline $\mathrm{Ca}^{2+}$ & 1000 & $99 \pm 3$ & $\mathrm{Mn}^{2+}$ & 1000 & $98 \pm 4$ \\
\hline $\mathrm{Mg}^{2+}$ & 1000 & $102 \pm 4$ & $\mathrm{Ba}^{2+}$ & 1000 & $100 \pm 2$ \\
\hline $\mathrm{Zn}^{2+}$ & 1000 & $103 \pm 3$ & $\mathrm{Fe}^{2+}$ & 25 & $98 \pm 3$ \\
\hline $\mathrm{Co}^{2+}$ & 750 & $95 \pm 2$ & $\mathrm{Br}$ & 1000 & $103 \pm 3$ \\
\hline $\mathrm{Pb}^{2+}$ & 25 & $96 \pm 2$ & $\mathrm{~F}^{-}$ & 1000 & $99 \pm 2$ \\
\hline $\mathrm{Cu}^{2+*}$ & 250 & $104 \pm 4$ & & & \\
\hline
\end{tabular}

*In the presence of glycine a molar ratio of 1000 was tolerated.

Table 2. Analytical characteristic of the method

\begin{tabular}{lc}
\hline Linear Dynamic Range & $3-250 \mu \mathrm{g} \mathrm{L}^{-1}$ \\
Correlation Coefficient/( $\left.\mathrm{R}^{2}\right)$ & 0.999 \\
Limit of detection & $0.3 \mu \mathrm{g} \mathrm{L}^{-1}$ \\
Limit of quantification & $1.0 \mu \mathrm{g} \mathrm{L}^{-1}$ \\
$\mathrm{RSD} /(\%)(\mathrm{n}=7)$ & $4.0\left(\right.$ at $\left.100 \mu \mathrm{g} \mathrm{L}^{-1}\right)$ \\
Preconcentration factor & 70 \\
Enhancement factor & 63 \\
\hline
\end{tabular}

analytical characteristics of the developed procedure are summarized in Table 2.

\section{Application}

The proposed procedure was applied to the determination of cadmium in tap water, well water and seawater. Reliability was checked by spiking the sample with known amount of cadmium, and comparing the results with those obtained by GFAAS analysis. The results are given in Table 3, as it could be seen, the recoveries of the spiked sample are good (95$102 \%$ ) and at $95 \%$ confidence level there is no significant difference between the results of developed procedure and GFAAS analysis. Furthermore, in order to verify the accuracy of the proposed procedure, it was used for determination of cadmium in reference ore material (CCU-1b) the results of which is also given in Table 3. The concentration of cadmium in the sample was found to be $173 \pm 4 \mu \mathrm{g} \mathrm{g}^{-1}$, which at $95 \%$ confidence level, is in good agreement with the certified value of $181 \pm 5.0 \mu \mathrm{g} \mathrm{g}^{-1}$. Thus the procedure is reliable for determination of cadmium in the sample types examined.

\section{Conclusions}

It was demonstrated that the ion pair of $\left[\mathrm{CdI}_{4}\right][\mathrm{MTOA}]_{2}$ can be quantitatively concentrated into surfactant rich phase in a single-step extraction. The proposed procedure provides a simple reliable and effective route for separation and preconcentration of cadmium and final determination by FI-FAAS in several categories of natural waters. Furthermore, determination of cadmium by developed procedure was compared with other CPE-FAAS ${ }^{21,22,24,25}$ and the results are summarized in Table 4. As it is shown the proposed procedure has higher enrichment factor and consequently lower detection limit (with the exception of LOD of reference 20). Thus it provides an alternative procedure to techniques such as GFAAS and ICP-MS for determination of cadmium at $\mu \mathrm{g} \mathrm{L}^{-1}$ level in water samples. The main advantages of the procedure are: safety, simplicity, low cost, good extraction efficiency and enhancement of FAAS sensitivity.

Table 3. Determination of cadmium in real samples

\begin{tabular}{lcccc}
\hline Sample & Added $/\left(\mu \mathrm{g} \mathrm{L}^{-1}\right)$ & Found $^{\mathrm{a}} /\left(\mu \mathrm{g} \mathrm{L}^{-1}\right)$ & Recovered $/(\%)$ & $\mathrm{GFAAS}^{\prime}\left(\mu \mathrm{g} \mathrm{L}^{-1}\right)$ \\
\hline Sea water & - & $1.8 \pm 0.4$ & - & 102.8 \\
Well water & 14 & $16.2 \pm 0.2$ & - & - \\
& - & $1.2 \pm 0.2$ & 98.6 & $1.32 \pm 0.12$ \\
Tap water & 14 & $15.0 \pm 0.8$ & - & - \\
& - & $\mathrm{ND}$ & 97.8 & $\mathrm{ND}$ \\
Standard ore $(\mathrm{CCU}-1 \mathrm{~b})^{\mathrm{b}}$ & 14 & 13.7 & 95.6 & - \\
\hline
\end{tabular}

${ }^{\mathrm{a}}$ Results are mean and standard deviation of three independent measurements. ${ }^{\mathrm{b}} \mathrm{Copper}$ flotation concentrate standard reference material with the composition of $\mathrm{Al}_{2} \mathrm{O}_{3}=0.188 \pm 0.012 \% ; \mathrm{CaO}=0.184 \pm 0.014 \% ; \mathrm{Ag}=178 \pm 2 \mu \mathrm{g} \mathrm{g}^{-1} ; \mathrm{As}=58 \pm 7 \mu \mathrm{g} \mathrm{g}^{-1} ; \mathrm{Au}=5.58 \pm 0.10 \mu \mathrm{g} \mathrm{g}^{-1} ; \mathrm{Cd}^{2} 181 \pm 5 \mu \mathrm{g} \mathrm{g}{ }^{-1}$. 
Table 4. Comparison of detection limit and enrichment factor of CPE-FAAS of cadmium

\begin{tabular}{lcccc}
\hline Ligand & Sample & LOD $/\left(\mu \mathrm{g} \mathrm{L}^{-1}\right)$ & Enrichment factor & Reference \\
\hline TAN & Water & 0.099 & 57.7 & 21 \\
TAN & Water & 0.75 & 20.3 & 22 \\
DDTP & Water and cigarette & 0.9 & - & 24 \\
Dithizone & Water & 0.31 & 52 & 25 \\
Methyltrioctylammonium chloride & Water and reference ore & 0.3 & 63 & Present work \\
\hline
\end{tabular}

DDTP: $O, O$-diethyldithiophosphate;TAN: 1-(2-thiazolylazo)-2-naphtol; LOD: limit of detection.

\section{References}

1. Silva, J. B. B. da; Borges, D. L. G.; Veiga, M. A. M. S. da; Curtius, A. J.; Welz, B.; Talanta 2003, 60, 977.

2. Baird, C.; Environmental Chemistry, $2^{\text {nd }}$ ed., Freeman, W. H. and Company: New York, 1999.

3. Asadoulahi, T; Dadfarnia, S.; Haji Shabani, A. M.; J. Braz. Chem Soc. 2007, 18, 1353.

4. Dadfarnia, S.; McLeod, W.; Appl. Spectrosc.1994, 48, 1331.

5. Bortoleto, G. G.; Macarovscha, G.T.; Cadore, S.; J. Braz. Chem. Soc. 2004, 15, 313.

6. Li, Z.; Zhou, L.; J. Braz. Chem. Soc. 2008, 19, 1347.

7. Maranhão, T. de. A.; Martendal, E.; Borges, D. L. G.; Carasek, E.; Welz, B.; Curtius, A. J.; Spectrochim. Acta, Part B 2007, 62, 1019.

8. Ferreira, A. C.; Korn, M. G. A.; Ferreira, S. L. C.; Microchim. Acta 2004, 146, 271.

9. Baghban, N.; Haji Shabani, A. M.; Dadfarnia, S.; Jafari, A. A.; J. Braz. Chem. Soc. 2009, 20, 832.

10. Bezerra, M. de. A.; Conceição, L. B. A.; Ferreira, S. L. C.; Microchim. Acta 2006, 154, 149.

11. Silva, M. F.; Cerutti, E. S.; Martinez, L. D.; Microchim. Acta 2006, 155, 349.

12. Bezerra, M. de A.; Arruda, M. A. Z.; Ferreira, S. L. C.; Appl. Spectrosc. Rev. 2005, 40, 269.

13. Watanabe, H.; Tanaka, H.; Talanta 1978, 25, 585.
14. Teo, K. C.; Chen J.; Analyst 2001, 126, 534.

15. Doroschuk, V. O.; Lelyushok, S. O.; Ishchenko, V. B.; Talanta 2004, 64, 853.

16. Nascentes, C. C.; Arruda, M. A. Z.; Talanta 2003, 61, 759.

17. Ferreira, H. S.; Bezerra, M. de. A.; Ferreira, S. L. C.; Microchim. Acta 2006, 154, 163.

18. Gaudarzi, N.; J. Braz. Chem. Soc. 2007, 18, 1348.

19. Afkhami, A.; Madrakian, T.; Siampour, H.; J. Braz. Chem. Soc. 2006, 17, 797.

20. Afkhami, A.; Madrakian, T.; Siampour, H.; J. Hazard. Mater. 2006, 138, 269.

21. Chen, J.; Teo. K. C.; Anal. Chim. Acta 2001, 450, 215.

22. Silva, E. L.; Roldan, P. D. S.; J. Hazard. Mater. 2009, 161, 142.

23. Manzoori, J. L.; Bavili-Tabrizi, A.; Anal. Chim. Acta 2002, 470, 215.

24. Coelho, L. M.; Arruda, M. A. Z.; Spectrochim. Acta, Part B 2005, 60, 743 .

25. Manzoori, J. L.; Karim-Nezhad, G.; Anal. Chim. Acta 2004, 521,173

26. Lurie J.; Handbook of Analytical Chemistry, English Translation, Mir Publisher: Moscow, 1975.

27. Dadfarnia, S. Haji Shabani, A. M. Kamranzadeh, E; Talanta 2009, 79, 1061.
Submitted: May 12, 2010

Published online: July 29, 2010 